NASA Technical Memorandum 102563

\title{
Nicalon/Siliconoxycarbide Ceramic Composites
}

Frances I. Hurwitz

Lewis Research Center

Cleveland, Ohio

John_Z. Gyekenyesi and Paula J. Conroy

Cleveland State University

Cleveland, Ohio

Ann L. Rivera

Case Western Reserve University

Cleveland, Ohio

Prepared for the

14th Annual Conference on Composites and Advanced Ceramics

sponsored by the American Ceramic Society

Cocoa Beach, Florida, January 14-17, 1990

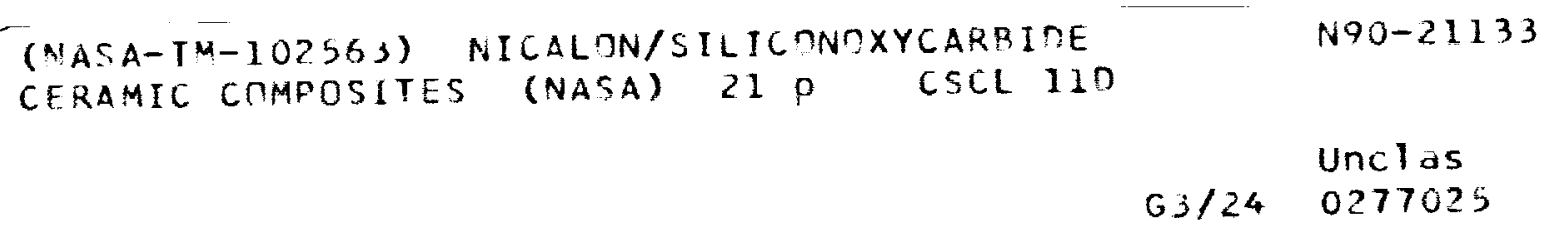


. 


\title{
NICALON/SILICONOXYCARBIDE CERAMIC COMPOSITES
}

\author{
Frances I. Hurwitz \\ National Aeronautics and Space Administration \\ Lewis Research Center \\ Cleveland, Ohio 44135
}

John Z. Gyekenyesi and Paula J. Conroy

Cleveland State University

Cleveland, Ohio 44115

Ann L, Rivera

Case Western Reserve University

Cleveland, Ohio 44106

\begin{abstract}
A series of silsesquioxane copolymers has been synthesized by acid hydrolysis and condensation of trimethoxysilanes of the form RSi(OCH$)_{3}$, where $\mathrm{R}=$ methyl or phenyl. By varying $\mathrm{pH}$, water/methoxy and methyl/phenyl ratios, the molecular structure, polymer rheology and ceramic composition can be controlled. The polymers form an amorphous siliconoxycarbide on pyrolysis. Composites of Nicalon/siliconoxycarbide were fractured in four-point flexure and in tension to evaluate the influence of matrix composition, final fabrication temperature and use of filler on composite mode of failure, modulus, strain capability and strength. Incorporation of filler was found to increase matrix compressive strength. Employment of processing temperatures of $1375-1400^{\circ} \mathrm{C}$ enhanced strain to failure and reduced the tendency toward brittle fracture. Mixed mode (compression/shear and tension/shear) failures were observed in flexural samples processed to the higher temperatures, giving rise to nonlinear stress-strain curves. Tensile samples pyrolyzed to $1400{ }^{\circ} \mathrm{C}$ showed linear-elastic behavior and failed by fracture of fiber bundles. Matrix material was found to be adherent to the fiber surface after failure. These results demonstrate the need for tensile testing to establish composite behavior.
\end{abstract}


Introduction

Nicalon/siliconoxycarbide composites currently are being investigated as potential materials for structural applications in the $1000-1400^{\circ} \mathrm{C}$ temperature range. The use of polymeric precursors to the matrix permits tailoring of the polymer molecular structure and rheology. Resins of varying viscosity can be produced that are suitable for various composite fabrication techniques, including casting from solvent into the fiber tow in filament winding and impregnation of cloths and $3 D$ preforms. Resin viscosity might also be varied during fabrication of the same piece, using a more viscous material for the first impregnation cycle, and progressing to more fluid resins on successive reimpregnation steps. In addition, initial fabrication can be carried out at low temperatures (several hundred degrees celsius), utilizing technology available from the resin matrix composite industry. The polysilsesquioxanes used in this study are readily synthesized by hydrolysis and condensation of phenyl- and methyltrimethoxysilanes. ${ }^{1}$ The polymers can be handled under ambient conditions for composite fabrication. They can be pyrolyzed to form amorphous glasses which are thermally stable to $1400^{\circ} \mathrm{C} .^{2}$ At higher temperatures (above $1450^{\circ} \mathrm{C}$ ) they undergo 
carbothermal reduction to form $\beta$-sic. The formation of nanocrystallites of $\beta-S i C$ has been shown to precede observable weight loss, and the ease of crystallization to vary with initial copolymer composition. ${ }^{2}$

The objective of the present study was to screen a number of polymers of differing molecular structure, viscosity and copolymer composition, and a variety of processing schedules, for the production of strong, tough, Nicalon/siliconoxycarbide composites. In these initial studies a single impregnation/pyrolysis cycle was used, so as to limit the number of materials selected for further densification studies and optimization of composite properties. Therefore, the mechanical properties of the composite materials presented here should not be looked upon as representative of those attainable for a polymer-derived ceramic matrix composite system which has undergone further densification.

Variables during polymer synthesis included $\mathrm{pH}$ (ranging from 2 to 4 ), water/methoxy ratio and phenyl/methyl ratio. Final processing temperatures of the composites ranged from 1200 to $1400^{\circ} \mathrm{C}$. Incorporation of a filler in the matrix also was studied as a means of minimizing matrix shrinkage and cracking. The filler used was derived from pyrolysis of the 50 phenyl/50 methyl silsesquioxane copolymer pyrolyzed to $650^{\circ} \mathrm{C}$, then milled to $<1 \mu \mathrm{m}$ powder. 
Experimental

Polymer synthesis

Phenyl- and methyl-trimethoxysilanes were purchased from Petrarch systems and used without further purification.

Monomers were added to an acetic acid solution, stirred until the solution became clear, then maintained at $30^{\circ} \mathrm{C}$ in a water bath for 72 hours, by which time a viscous liquid polymer was found to have settled at the bottom of the flask. The polymer was cooled in a refrigerator to increase its viscosity, and excess water removed by decanting. Details of the synthesis and complete polymer characterization by Fourier transform infrared analysis, ${ }^{1} \mathrm{H},{ }^{13} \mathrm{C}$ and ${ }^{29} \mathrm{Si}$ nuclear magnetic resonance and gel permeation chromatography are reported separately ${ }^{1}$.

Composite fabrication

P-sized Nicalon fiber, available from Dow Corning corporation, was used in its as received condition (i. e. with the sizing). ${ }^{3}$ To form prepreg, fiber tows were wound on a mandrel. The polymer was dissolved in HPLC grade acetonitrile at a concentration of $50 \mathrm{gm}$ polymer per $40 \mathrm{ml}$ solvent. In those composites in which fillers were used, the filler was suspended in the polymer solution by vigorous stirring, and the weight of liquid polymer adjusted to maintain a total weight of 
polymer plus filler of $50 \mathrm{gm}$. The fiber tows were coated with the polymer solution and the solvent allowed to evaporate under ambient conditions. The resulting prepreg was then removed from the mandrel, cut into plies and stored in a freezer until ready to press.

Twelve ply composites were fabricated by stacking prepreg plies in a matched metal die mold, and pressing at $180^{\circ} \mathrm{C}, 689$ Pa for 2 hours. Composites were machined into test coupons and pyrolyzed at ambient pressure in flowing argon which had been passed through a Hydrox 8301 system (Matheson) to minimize oxygen content and avert cristobalite formation ${ }^{2}$. Holds of 2 hours and one hour were placed in the pyrolysis schedule at 525 and $700^{\circ} \mathrm{C}$, respectively, to permit full evolution of volatiles. Final pyrolysis temperatures varied from 1200 to $1400^{\circ} \mathrm{C}$; the final temperature was maintained for 30 minutes.

composite characterization

Mechanical property characterization was carried out in four-point flexure and in tension, using a screw-driven tension/compression load frame. Four-point flexural specimens nominally $102 \times 6.4 \times 2.3 \mathrm{~mm}$ were tested. The loading fixture had a fixed span of $25.4 \mathrm{~mm}$, and the sample was supported at a span of $79.4 \mathrm{~mm}$. Load and support fixtures both utilized 6.4 $\mathrm{mm}$ diameter rollers. Strain was measured by a strain gauge bonded to the tensile surface of the specimen. (Initial 
samples were run with strain gauges bonded on both tensile and compressive surfaces so that the respective moduli could be compared). The flexural samples were loaded at a crosshead rate of $0.13 \mathrm{~mm} / \mathrm{min}$. Modulus and first matrix cracking stress were calculated using beam theory.

Tensile properties were determined using straight-sided coupons nominally $127 \times 12.8 \times 2.3 \mathrm{~mm}$. Opposing strain gauges were bonded on either side of the sample to monitor bending. Loading was at a constant crosshead rate of $.013 \mathrm{~mm} / \mathrm{min}$. composite microstructures and fracture surfaces were examined by visible light and scanning electron microscopy (SEM) •

Thermo-oxidative stability of matrix

To assess the high temperature stability of the matrix in oxygen, bulk polymer first was pyrolyzed in flowing argon to $1400^{\circ} \mathrm{C}$ using the same schedule normally used in fabrication of composites. Chunks of the glassy pyrolyzed material were then heated isothermally in flowing oxygen $(34.35 \mathrm{~cm} / \mathrm{min})$ for 100 hours at temperatures of 1150 and $1250^{\circ} \mathrm{C}$, and their weight monitored continuously. 
Results and Discussion

Polymer characterization

Synthesis and characterization of the as-synthesized polymers is discussed in detail elsewhere ${ }^{l}$. All conditions of $\mathrm{pH}$ and water/methoxy ratios studied produced primarily low molecular weight oligomers, as determined by gel permeation chromatography. $M_{n}$ ranged from 900-1600, based on polystyrene standards. The $\mathrm{pH} 4$ materials showed some crosslinking, and were not fully soluble in acetonitrile. At pH 3, the polymer was fairly monodisperse, with number average molecular weights of 1000-1200. The formation of cyclic and cage structures appeared favored at $\mathrm{pH} 2$, based upon the high number of trifunctionally bonded and low fraction of monofunctionally reacted $s i$ nuclei, as seen by ${ }^{29} \mathrm{si}$ NMR. Some higher molecular weight species also were observed at this pH. $\left(M_{W}\right.$ ranged from 2300-2900). The $\mathrm{pH} 3$ materials were chosen for composite fabrication because they appeared to produce lower viscosity liquids best suited to the prepreg techniques used and for reinfiltration.

Polymer viscosity was seen to decrease with decreasing water/methoxy ratio over the range from $14.5-1.8$ moles water/mole methoxide. Two water/methoxide ratios were selected for composite fabrication: 14.5 and 3.6 . The polymer 
synthesized at the higher ratio (more viscous polymer) seemed well suited for filament winding, while the less viscous appeared a good candidate for later composite reimpregnation studies. Molecular weight distribution and polymer structure, as determined by ${ }^{29} \mathrm{Si}$ nuclear magnetic resonance ${ }^{1}$ were similar for both materials. Composites were fabricated using a single impregnation/ pyrolysis with both preceramic polymers to determine if any difference in composite mechanical properties could be observed.

Three copolymer compositions were chosen for composite fabrication: 30 phenyl/70 methyl, 50 phenyl/50 methyl, and 70 phenyl/30 methyl. The composition of the siliconoxycarbide produced on pyrolysis of silsesquioxane copolymers has been shown ${ }^{2}$ to vary with copolymer composition, such that the carbon content increases nonlinearly with phenyl content of the copolymer, producing amorphous glasses with carbon contents of 37, 44 and 52 atom percent, respectively, for the three copolymer compositions listed above. (Si decreased linearly from 26 to 23 atom percent with increasing phenyl content, and oxygen accounted for the remaining component).

Composite properties

Composites fabricated from the three copolymers discussed in the preceding paragraph were tested in four-point flexure 
following pyrolysis to $1200^{\circ} \mathrm{C}$. All exhibited linear-elastic, brittle behavior under this processing regime. For those specimens which had strain gauges bonded to both the tensile and compressive surfaces, the two moduli measured were equal within experimental error. Strength, modulus and strain to failure for the three materials are shown in Figure 1 . At 70 percent phenyl, the higher carbon content results in a decrease in modulus. Ultimate strains are nominally $0.12 \%$ for both the 50 and 70 phenyl compositions. Therefore, in the linear-elastic regime, the highest strength is achieved with the 50 phenyl/50 methyl matrix material. Hence, this polymer composition was the one chosen for further study. Comparison of the flexural behavior of the 50 phenyl/50 methyl matrix laminate pyrolyzed to $1200^{\circ} \mathrm{C}$ with specimens from the same panel pyrolyzed to $1400^{\circ} \mathrm{C}$ (Figure 2) shows that, as the final fabrication temperature is increased, the stress-strain behavior changes from linear-elastic to what appears to be a composite-like fracture. The apparent yield stress for the $1400^{\circ} \mathrm{C}$ material occurs at $219 \mathrm{MPa}$, higher than the ultimate failure stress of $179 \mathrm{MPa}$ observed in the $1200^{\circ} \mathrm{C}$ composite. The fracture mode changed from brittle to mixed compressive buckling and shear. Therefore, it was initially hypothesized that changes were occurring at the fiber-matrix interface. 
However, tensile tests of the same material (50 phenyl/50 methyl matrix, final fabrication temperature of $1400^{\circ} \mathrm{C}$ ), demonstrated Iinear stress-strain behavior. Bending stresses were on the order of $2.2 \%$. Although macroscopic examination of the fractured sample shows what appears to be fiber pullout (Figure 3), closer examination of the fracture surface by scanning electron microscopy (Figure 4) reveals that the matrix is still well bonded to the fiber. Failure is by bundle fracture, with shearing taking place within the matrix, rather than at the interface. The composite-type behavior inferred from the flexural stress-strain curve therefore must be attributed to mixed mode failure. The apparent yield point arises from compressive buckling and delamination, resulting in a shifting of the neutral axis to produce the change in slope, and is an artifact of the flexural loading, rather than a true "composite" fracture.

All the matrix materials discussed to this point were synthesized in a large excess of water, having 14.5 moles water per mole methoxide. Since the polymer viscosity was found to decrease on reducing the water/methoxide ratio, and because a less viscous resin was desirable for reimpregnation studies and for use with fillers, which tend to increase resin viscosity, laminates also were fabricated from polymer 
synthesized at $1 / 4$ the water/methoxide, at a ratio of nominally 3.6. These were then tested in flexure after pyrolysis to final temperatures of 1300,1350 and $1400^{\circ} \mathrm{C}$.

strength, modulus and stress-strain behavior for these latter composites were comparable to those for composites synthesized at the 14.5 water/methoxide ratio discussed previously. Linear elastic behavior was seen at the 1300 and $1350^{\circ} \mathrm{C}$ fabrication conditions, while nonlinear behavior was observed after heating to $1400^{\circ} \mathrm{C}$. Stress-strain curves similar to those shown in Figure 2 were obtained. The data for these laminates is summarized in the first three pairs of bars in Figure 5 (those labelled as containing "o" filler). Increasing the final fabrication temperature to $1400^{\circ} \mathrm{C}$ is shown to increase the strain to matrix failure, and hence the first matrix cracking strength of the composite.

Incorporation of fillers was studied in an attempt to reduce matrix shrinkage and cracking, and hence increase matrix strength. A filler derived from the same polymeric precursor was chosen so that, in the final composite, there would be no mismatch in coefficient of thermal expansion between the filler and matrix. Two levels of filler loading were selected for study: $10 \mathrm{gm}$ filler/40 $\mathrm{gm}$ polymer and $5 \mathrm{gm}$ filler/45 gm polymer.

Flexural properties of the material with $10 \mathrm{gm}$ of filler heated to final fabrication temperatures of 1300,1350 and 
$1400^{\circ} \mathrm{C}$ are shown in the second group of three pairs of bars in Figure 5. An increase in strength and strain to failure with final fabrication temperature, similar to that for the unfilled matrix, is observed. However, examination of fracture surfaces reveals differences in the mode of failure between the unfilled and filled materials at each temperature.

At $1300^{\circ} \mathrm{C}$, behavior is linear elastic for both materials, and brittle fracture is observed. However, while the unfilled material fails as fiber bundles (Figure 6a), the filled matrix shows a more planar fracture (Figure $6 b$ ). The filler particles themselves could not be seen as distinct from the matrix by scanning electron microscopy, even at magnifications of up to 15,000x. Examination of polished surfaces by light microscopy illustrates differences in composite microstructure on filler addition (Figure 7). Matrix cracking still occurs, but surrounds larger areas, accounting for the more planar fracture surface seen in the filled material. The filler increases resin viscosity, thus producing matrix-rich regions and effectively decreasing the average fiber volume fraction, which would explain the observed decrease in strength as compared with the unfilled composite (see Figure 5).

Fracture behavior at $1350^{\circ} \mathrm{C}$ is similar to that at $1300^{\circ} \mathrm{C}$. However, at $1400^{\circ} \mathrm{C}$, although stress-strain behavior is still linear-elastic in the filled material, the mode of fracture changes. A mixture of compressive failure over the load point 
and shear outside the gauge section is observed for the unfilled composite (Figure 8a), while the filled material fails in tension and shear outside the gauge section (Figure 8b). Thus incorporation of filler appears to increase the compressive strength of the matrix, enabling sufficiently high stress levels to be attained for tensile fracture to occur.

Composites fabricated at a lower filler loading $(5 \mathrm{gm}$ filler $/ 45 \mathrm{gm}$ polymer) and heated to $1375^{\circ} \mathrm{C}$ exhibited nonlinear stress-strain behavior when tested in four-point flexure (see Figures 5 and 9), failing in mixed tension and shear. Flexural modulus ( $109 \mathrm{GPa}$ ) was similar to that of the composite with 10 gm of filler, but lower than that of the unfilled material (Figure 9), again suggesting that the effective fiber volume fraction is slightly reduced. Tensile samples showed linear-elastic behavior, with shearing between the plies, and strengths of nominally $128 \mathrm{MPa}$.

Matrix thermo-oxidative stability

Isothermal exposure of the siliconoxycarbide matrix material for 100 hours at 1150 and $1250^{\circ} \mathrm{C}$ (Figure 10) demonstrated that while the matrix material is quite stable to oxygen at $1150^{\circ} \mathrm{C}$, maintaining $99.6 \%$ of its initial weight over the 100 hour period, at $1250^{\circ} \mathrm{C}$ the material is stable for the first several hours, but then loses about $12 \%$ of its initial weight between -10 and 100 hours. At 100 hours the weight has 
not yet stabilized. Both the 1150 and $1250^{\circ} \mathrm{C}$ samples exhibited silica on their outer surfaces. The higher temperature sample showed considerably more crystalline silica by $x$-ray diffraction than did the $1150^{\circ} \mathrm{C}$ exposed material. The weight loss at $1250^{\circ} \mathrm{C}$ is likely the result of loss of carbon from the matrix, which would be consistent with the observed $\alpha$-cristobalite formation.

Summary and conclusions

Polysilsesquioxanes can be pyrolyzed to amorphous siliconoxycarbides whose composition varies with the composition and structure of the starting polymer. Polymer viscosity can be tailored to suit various composite fabrication approaches by control of $\mathrm{pH}$ and water/methoxide ratio during synthesis. Over the range from 3.6-14.5 moles water/mole methoxide, tailoring the rheological behavior does not appear to influence composite properties significantly. The siliconoxycarbide matrix appears to be stable in air for a prolonged period ( 100 hours) at $1150^{\circ} \mathrm{C}$. However, the observed weight loss in a $1250^{\circ} \mathrm{C}$ oxidative environment suggests that the composite may require protective coating.

Final fabrication temperature for the laminate influences composite strength and mode of fracture, apparently by changes 
which occur in the matrix itself rather than at the fiber/matrix interface.

The matrix formed by a single impregnation/pyrolysis cycle is porous and weak. Its compressive strength can be increased by the addition of fillers. However, filler addition increases resin viscosity, yielding thicker composites for any given number of plies, and hence lower fiber volume fraction per unit cross section. By enhancing the compressive strength of the matrix, flexural properties appear to improve. Examination of failed flexural specimens indicates that the nonlinear stress-strain behavior is a result of mixed mode fracture, and does not carry over to tensile behavior, which remains linear-elastic. Use of flexural testing therefore needs to be approached with caution, and can be misleading.

The linear-elastic, low strength and toughness behavior of these composites leads to the conclusion that tailoring of the interface needs to be addressed to achieve fiber pullout and provide toughness, as does reimpregnation to increase matrix density, strength and modulus.

Acknowledgments

The authors wish to thank Earl R. Hanes, Jr., Stephen Roush and Donald L. Humphrey for their technical assistance. 


\section{References}

1. P. J. Conroy, A. L. Rivera and F. I. Hurwitz, "Polysilsesquioxanes as Precursors to Ceramics: Polymer synthesis and characterization," in preparation.

2. A. L. Rivera, F. I. Hurwitz, F. M. Terepka, S. C. Farmer and P. J. Conroy, "Polysilsesquioxanes as Precursors to Ceramics: Pyrolysis and Ceramic Characterization," to be submitted to Chemistry of Materials.

3. F. I. Hurwitz, J. Z. Gyekenyesi and P. J. Conroy, "Polymer Derived Nicalon/Si-C-O Composites: Processing and Mechanical Behavior," Ceram. Eng. Sci.Proc. 10, 750-763 (1989).

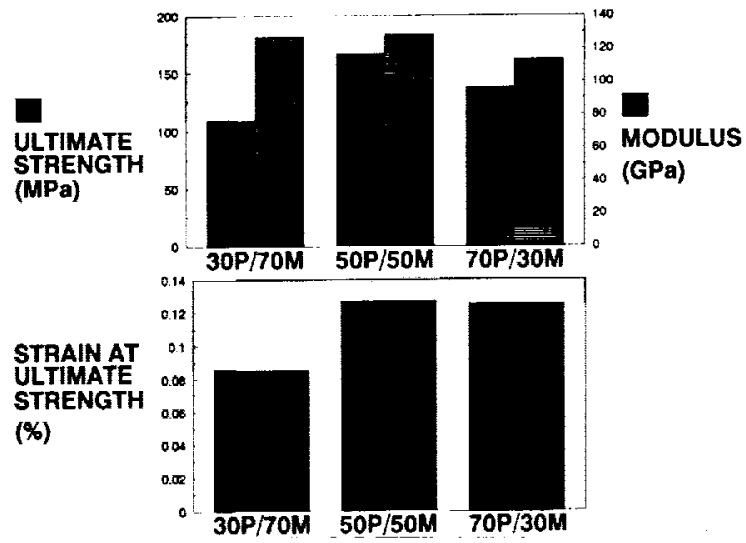

Figure 1. - Influence of matrix composition on flexural properties of Nicalon/siliconoxycarbide composites. Samples were pyrolyzed to $1200^{\circ} \mathrm{C}$ in argon, then tested at room temperature. Data points represent an average of four to five samples. The 50 phenyl/50 methyl material was fabricated twice to demonstrate reproducibility. Samples from both panels exhibited similar mechanical properties, within experimental error.

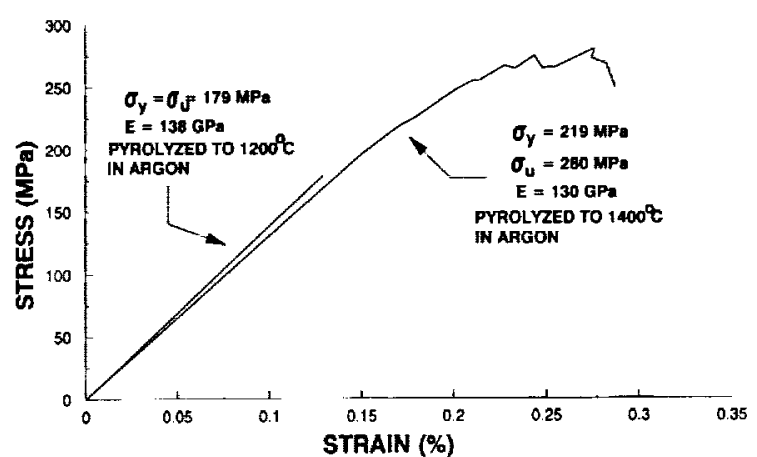

Figure 2. - Elfect of processing temperature on four-point flexural properties of Nicalon/siliconoxycarbide composites. 


\section{ORIGINAL PAGE \\ BLACK AND WHITE PHOTOGRAPH}
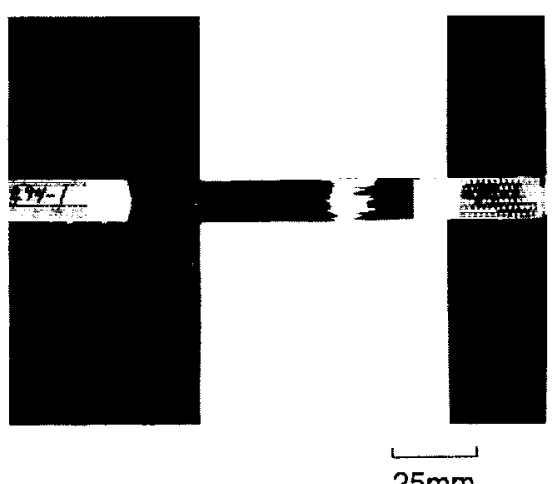

$\sigma=246 \mathrm{MPa}$

$\mathrm{E}=141 \mathrm{GPa}$

$\varepsilon=.17 \%$

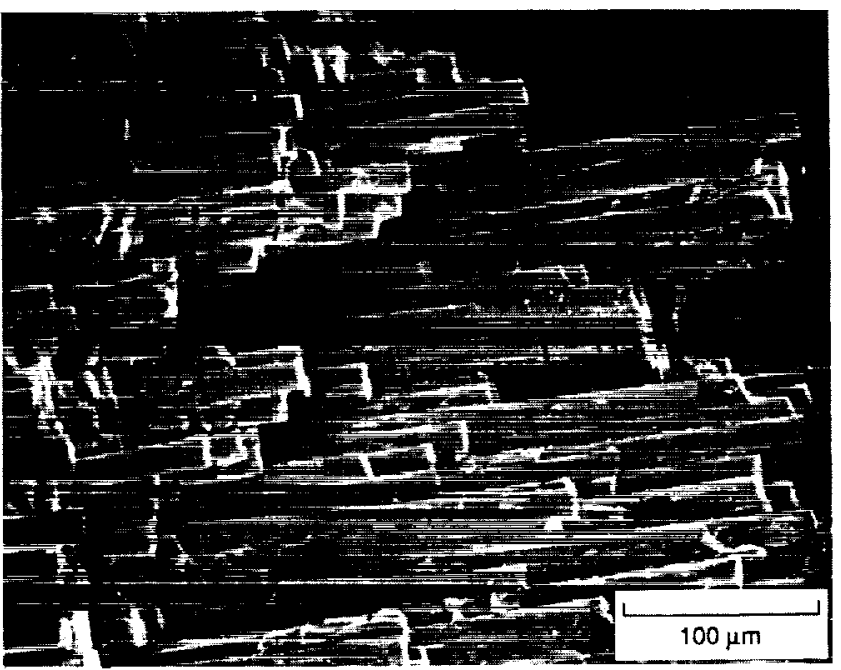

(a) Unfilled.

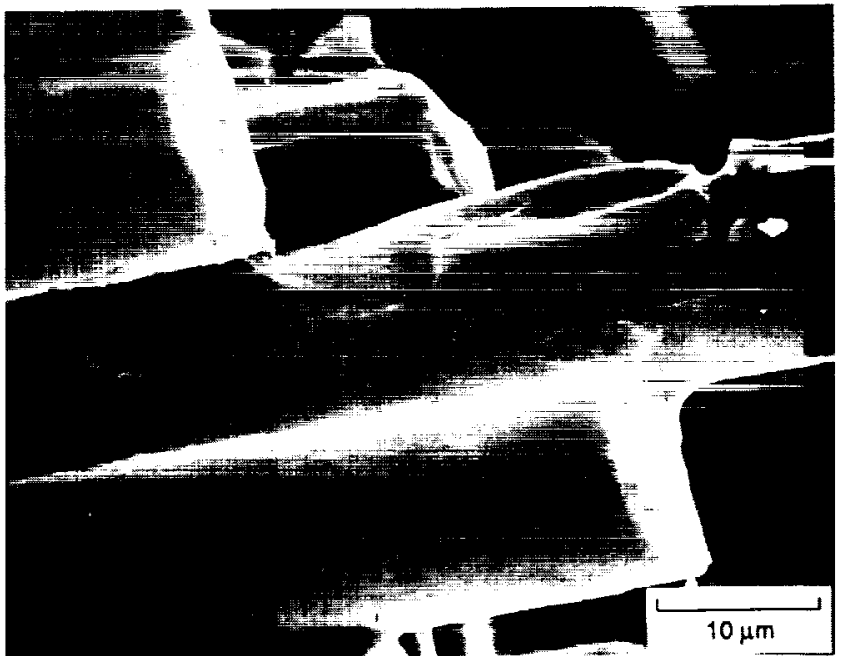

(b) Filled.

Figure 4 - Fracture surfaces of Nicalon/siliconoxycarbide composite pyrolyzed to $1400^{\circ} \mathrm{C}$ and tested at room temperature. Material the same as that in Figure 3. 


\section{ORIGINAL PAGE \\ BLACK AND WHITE PHOTOGRAPH}

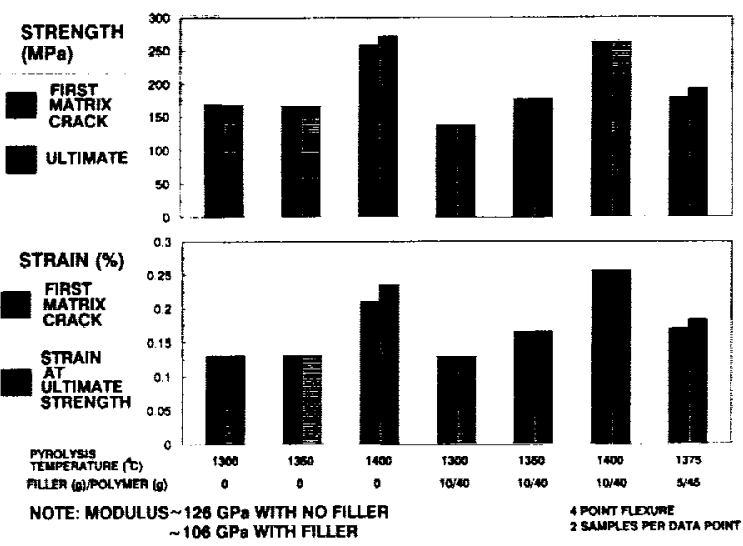

Figure 5. - Influence of pyrolysis temperature and filler loading on flexural properties of Nicalon'siliconoxycarbide composites. Each bar represents the average of two samples. Matrix derived from 50 phenyl/50 methyl silsesquioxane copolymer, 3.6 water/methoxide ratio.

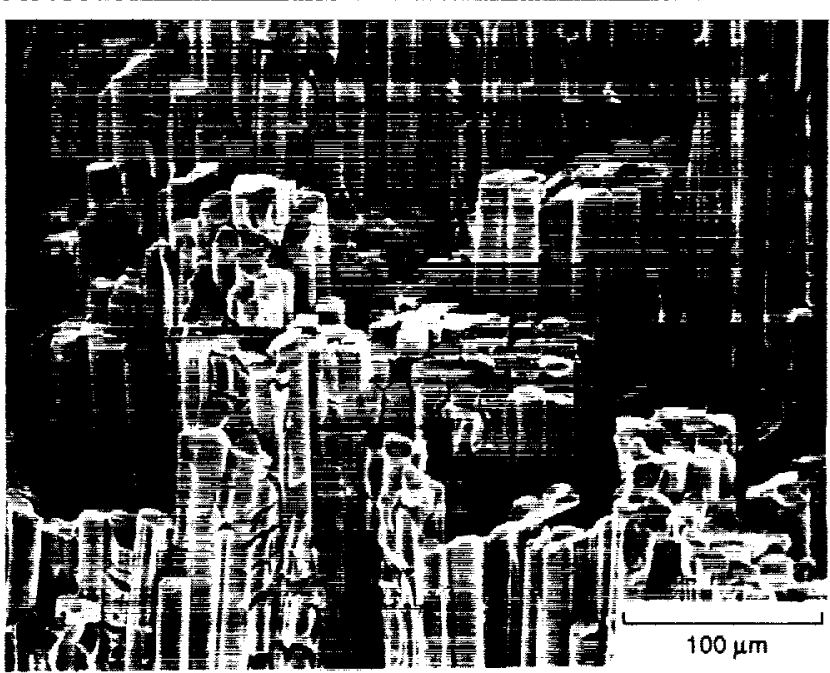

(a) Unfilled

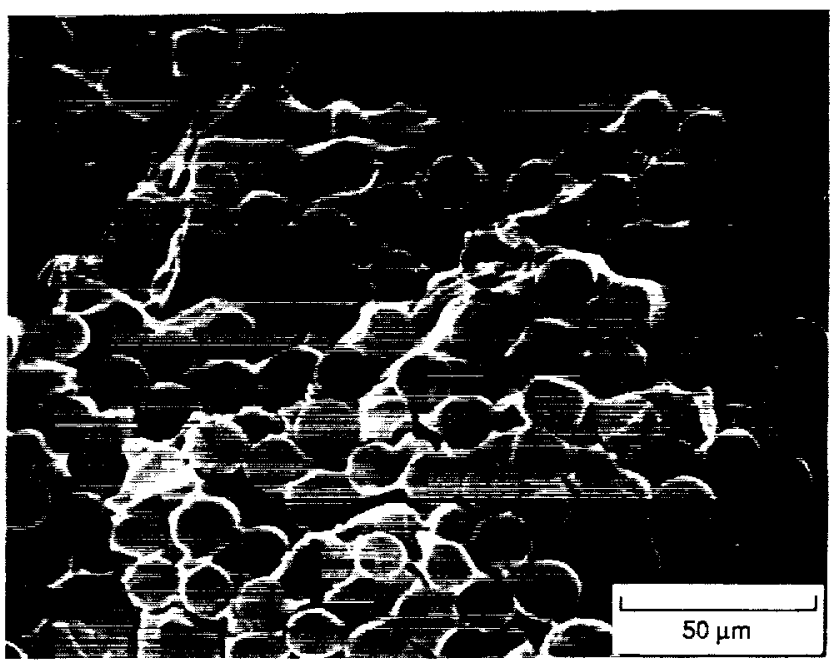

(b) Filled.

Figure 6. - Fracture surfaces of Nicalon/siticonoxycarbide composites pyrolyzed to $1300^{\circ} \mathrm{C}$ and fractured in four-point flexure at room temperature. Matrix derived from 50 pheny 150 methyl copolymer synthesized at 3.6 moles water/mole methoxide. 


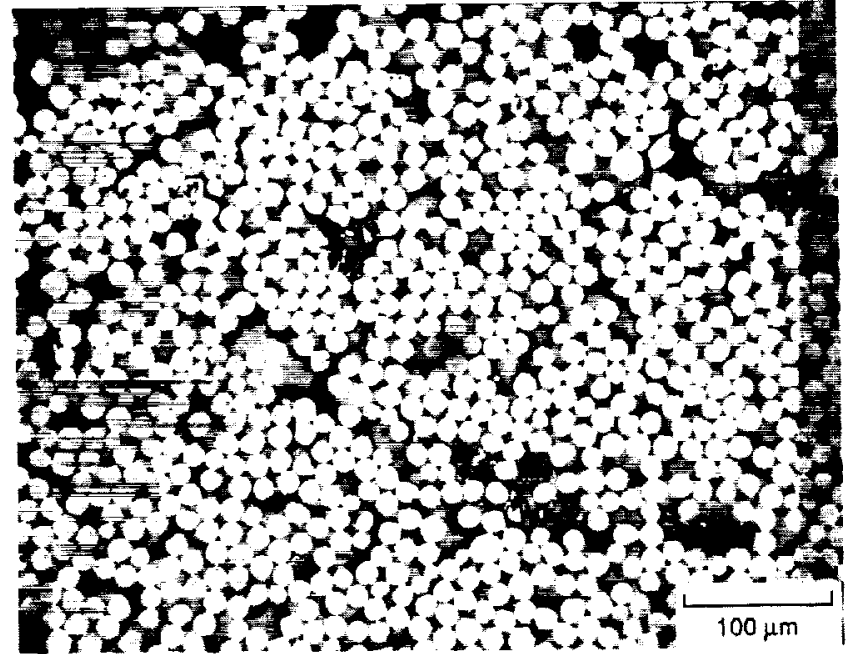

(a) Untilled.

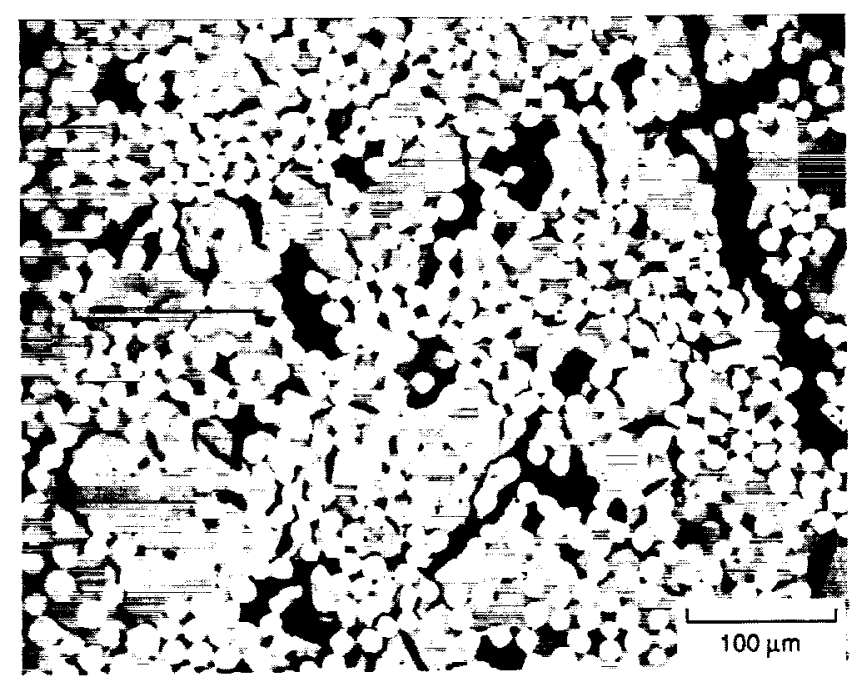

(b) Filled.

Figure 7. - Polished cross-sections of Nicalon/siliconoxycarbide composites after pyrolysis to $1300^{\circ} \mathrm{C}$ in argon.

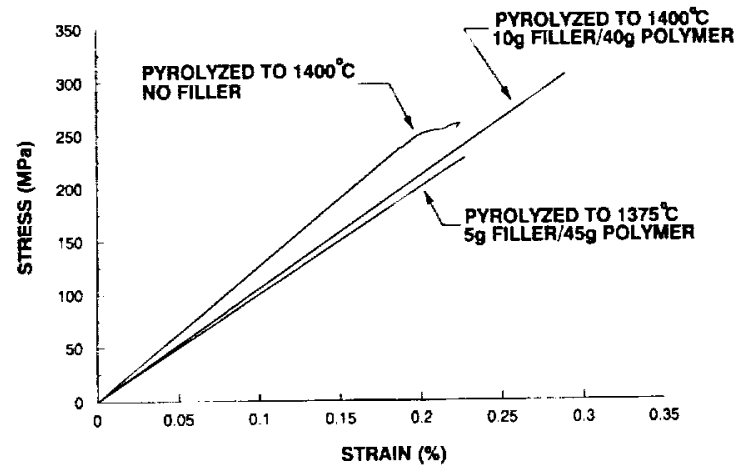

Figure 9. - Variation in stress-strain behavior of Nicalon/ siliconoxycarbide composites with filler addition. Sam ples were tested in four-point flexure at room temperature. Two samples were tested in each condition; stress-strain curves shown are representative.

\section{ORIGINAL: PAGE \\ BLACK AND WHITE PHOTOGRAPH}

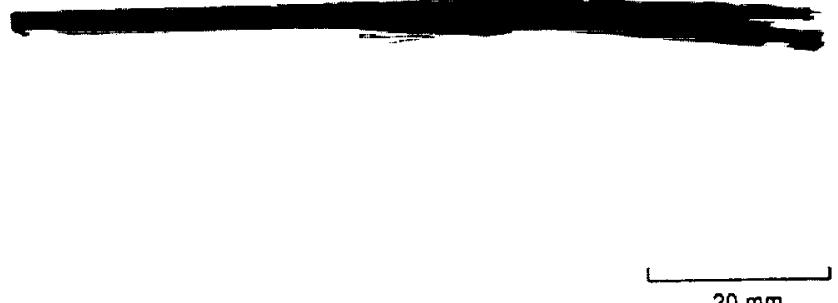

(a) Unfilled.

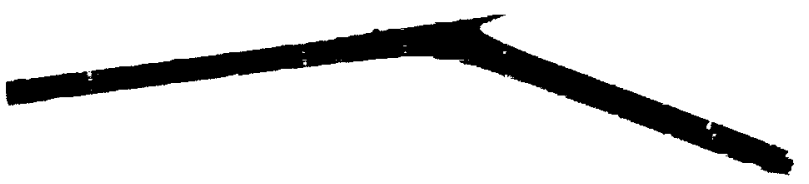

(b) Composite with $10 \mathrm{gm}$ filler

Figure 8. - Nicalon/siliconoxycarbide composites pyrolyzed to $1400^{\circ} \mathrm{C}$ fractured in four-point flexure at room temperature.

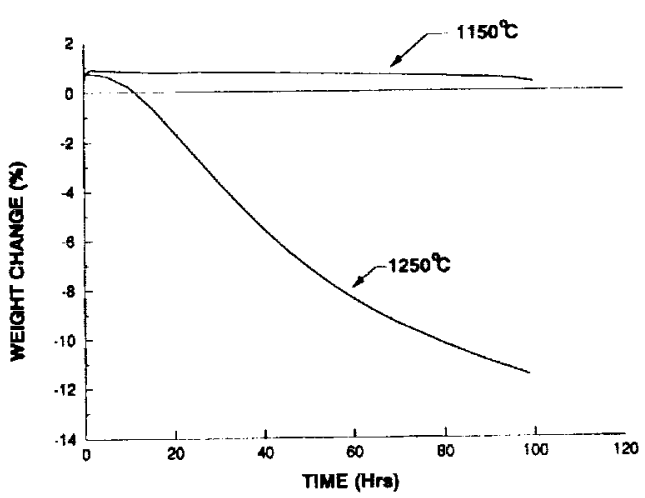

Figure 10. - Isothermal weight change in flowing oxygen of siliconoxycarbide initially pyrolyzed to $1400^{\circ} \mathrm{C}$ in argon. 


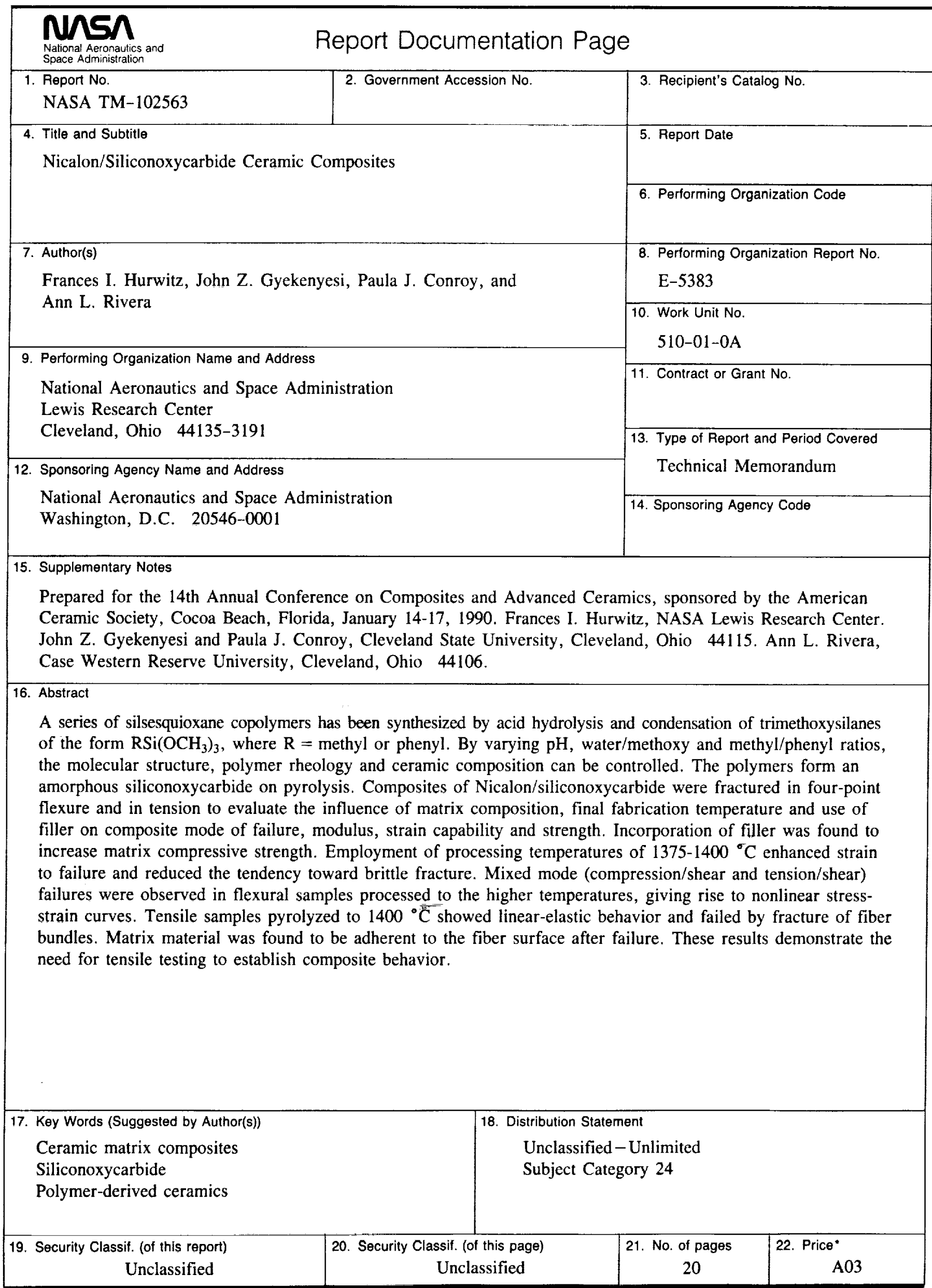

